\title{
On the Subjectivity and Intersubjectivity of Language
}

\author{
Li Feng \\ School of Foreign Languages, Shanxi University, Taiyuan, China
}

Email address:

mapleli@sxu.edu.cn

\section{To cite this article:}

Li Feng. On the Subjectivity and Intersubjectivity of Language. Communication and Linguistics Studies. Vol. 6, No. 1, 2020, pp. 1-5. doi: 10.11648/j.cls.20200601.11

Received: December 20, 2019; Accepted: January 2, 2020; Published: January 9, 2020

\begin{abstract}
When uttering a sentence, the speaker not only objectively expresses the propositional content of the sentence, but also conveys his views, feelings and attitudes toward the sentence. The speaker's imprint is inherent in language. However, due to the dominance of structural linguistics and formal linguistics for a long time, "the speaker's factor" in language has not been given due attention. With the advent of "linguistic turn" in the $20^{\text {th }}$ century, language has become one of the objects of philosophical research and the significance of "the speaker's factor" in language has attracted a host of scholars from philosophy, ethics, psychology, linguistics and many other disciplines. This paper firstly explores the mostly-acknowledged definition of subjectivity of language put forward by pioneering linguists, then discusses different approaches to the subjectivity of language from pragmatics, Relevance Theory, cognitive linguistics and Systemic Functional Grammar. Based on the previous research, the paper further explicates the speaker's subjectivity from three aspects, viz. the speaker's perspective, the speaker's affect, and the speaker's epistemic status. Lastly, the paper probes into the definition and development of intersubjectivity of language and points out that "the speaker's factor" in language has been and will definitely be a vital topic in the future linguistic research.
\end{abstract}

Keywords: Subjectivity, Speaker's Perspective, Speaker's Affect, Speaker's Epistemic Status, Intersubjectivity

\section{Introduction}

At the beginning of last century, Bréal proposed "subjectivity" as a linguistic phenomenon [4]. In the 1930s and 1950s, Bühler and Jakobson respectively described this phenomenon $[5,12]$. In the past four decades, people have begun to realize that language can not only objectively express propositional ideas, but also convey the speaker's views, feelings and attitudes. As Benveniste says, "language is marked so deeply by the expression of subjectivity that one might ask if it could function and be called language if it were constructed otherwise" [3]. After Benveniste, Lyons makes a further explanation of "subjectivity". He holds that "in making an utterance, the speaker simultaneously comments upon that utterance and expresses his attitude to what he is saying. This notion of subjectivity is of great importance, as we shall see, for the understanding of both epistemic and deontic modality" [17]. "subjectivity denotes the property (or set of properties) of being either a subject of consciousness (i.e., of cognition, feeling and perception) or a subject of action (an agent). It denotes the property of being what Descartes himself called a 'thinking entity' and identified, as others have done, with the self or the ego" [18]. According to Lyons, what the linguist pays attention to is, more specifically, locutionary subjectivity: the subjectivity of utterance.

However, due to the dominance of structural linguistics and formal linguistics for a long time, "subjectivity" has not been given due attention. Linguists regard the "objective" expression of propositions as the function of language and ignore the subjective component of self-expression in discourse. Therefore, the study of "subjectivity" of language remains in the scope of literature study at most and does not enter into the field of linguistics [30]. This paper is aimed to reiterate the importance of subjectivity and intersubjectivity and expound the definition and implication of subjectivity and intersubjectivity based on the previous relevant research.

\section{Research Approaches to the Subjectivity of Language}

As early as in ancient Greece, Protagoras affirms the important role of human beings in the process of knowing things. The famous maxim "man is the measure of all things" not only means people often utilize body parts to express and 
understand other things, but also means meaning is closely related to people's subjective knowledge, and meaning cannot be independent of the body [33]. For contemporary linguistics, how to understand human factors is a fundamental difference between functional semantics and formal semantics. Formal semantics studies the truth value of proposition and its conditions, and regards the essence of meaning as the correspondence between symbol and world. Functional linguistics studies utterance and regards the essence of meaning as man's understanding of experience.

Pragmatics pays much attention to "subjectivity", which is closely related to the study of the school of ordinary language philosophy. Later Wittgenstein puts forward the slogan of "meaning is use", that is, the meaning of a word is not determined by its reference but by its usage or its function. Its essence is to bring forward the connection between language and the language user's activity. Austin's speech act theory emphasizes that "saying is doing", as the speaker uses language to state facts, which is a kind of act of statement or description. Searle points out that the main feature of language communication is the intentionality of the subject [1]. Grice proposes the conversational "cooperative principle", emphasizing the speaker's meaning in communication. He believes that to understand the speaker's implicit meaning in utterance, people don't rely on linguistic decoding, but on pragmatic inference. It can be seen that no matter what form of research on meaning, the speaker's subjective intention is regarded as the decisive factor of meaning [9].

According to Relevance Theory, communication is the process of expressing and recognizing intentions, that is to say, the speaker provides evidence for the intention of delivering a certain meaning, and the recipient deduces the intention of the speaker on the basis of the evidence. Meaning is intention. The purpose of communicating a thought is to let the audience understand the communicator's intention of transmitting the thought. There are two kinds of intentions involved in language communication: informative intention and communicative intention. Informative intention refers to "an intention to inform"; communicative intention refers to "the intention to have one's informative intention recognized" [29]. Communicative intention is the second-order informative intention. Once the first-order informative intention is recognized by the audience, communicative intention can be realized. However, even if the informative intention is not realized, the communicative intention can still be realized.

Cognitive linguistics emphasizes the reflection of the subjective construal of human as a cognitive subject in language structure and meaning, and holds that human subjectivity has something in common with what psychologists call "anthropocentrism" or "egocentricity". Human play a central role in the perception of time, space and the construction of language [7], and place ego at the center of the universe, using it as a reference to form perspective to determine the concepts of "up and down, front and back, left and right, high and low, near and far, center and edge" [20]. In addition, cognitive linguistics equates meaning with conceptualization based on bodily experience, and points out that "the subjective aspect of semantic analysis is people's conceptualization, and the structure we care about is the structure that a person imposes on his/her mental experience through active cognitive processing" [14].

Systemic Functional Grammar (SFG) discusses the social constructivity of language from the interaction between people and social environment and between people in the social environment [10]. Its main idea is: as a member of a cultural group, the speaker may have a certain range of behavior potential in a certain social structure, which is reflected in the language as the meaning potential and is attributed to the lexical-grammar potential [6]. The hierarchical relationship among these three potentials shows that SFG emphasizes the way in which the speaker chooses from the lexical-grammatical potential of a language and reacts to others, society and the whole world.

It is evident that the above schools, which emerged, developed and became the mainstream of linguistic research in the middle and late 20th century, all center around "human factor". In a nutshell, language plays an intermediary role in the world, language and human system. People use language to connect with the world. That is to say, the production, development and operation of language are inseparable from human beings. Human is the first factor in language research. Language is human language and human is the essence of language [15].

\section{The Subjectivity of Language}

For subjectivity, the definition quoted by Shen Jiaxuan is widely used in Chinese linguistic circle, viz. "subjectivity is the characteristic of language. When making an utterance, the speaker simultaneously expresses his position, attitude and feelings towards the utterance, thus leaving his own mark in the utterance" $[8,30]$. This linguistic view emphasizes the participation of the cognitive subject's perspective and the important role of the speaker's subject consciousness in linguistic representation. Finegan holds that "subjectivity" is a concept opposite to "objectivity", which "concerns expression of self and the representation of a speaker's (or, more generally, a locutionary agent's) perspective or point of view in discourse - what has been called a speaker's imprint". At present, the research on subjectivity mainly focuses on (1) the speaker's perspective, (2) the speaker's affect, (3) the speaker's expression of the modality or epistemic status of the propositions [8]. Actually, these three aspects are intersected and connected with each other and and it is hard to draw a sharp distinction between them. In what follows, we will explicate them respectively for clarity of research.

\subsection{The Speaker's Perspective}

Research on "perspective" is concerned with philosophy, psychology, linguistics, poetics and art. Terms related to "perspective" include "point of view/viewpoint", "focalization", "seeing eye", "filter", "narrative perspective", "focus of narration", etc. For free translation, these terms can be roughly translated into "perspective". 
In Langacker's cognitive grammar, perspective is classified as a kind of understanding operation under focal adjustments, that is, perspective is a dimension of understanding and a way to observe a situation, including figure/ground alignment, viewpoint and subjectivity [14]. Figure/ground arrangement can be understood as that when people observe a situation, they will choose something as the focus of observation, which is the figure. Other things in the scenario focus on the focus and provide background for observing the focus. Viewpoint refers to people's observation of the position of things. Different observation positions lead to different observation results. As for subjectivity, it is a kind of perspective, also belongs to the category of construal, and is one of the cognitive abilities and ways for people to understand the world.

"Perspective is ubiquitous in utterance, because any utterance is expressed from the perspective of its participants, and these perspectives can be the reflection of its participants' spatiotemporal position, knowledge, belief, views, positions and attitudes" [16]. Just as Sanders and Redeker put it, "if we define the discourse perspective as a specific vantage point or point of view in a broad sense, then strictly speaking, no sentence in a discourse can be separated from a certain degree of perspectivization" [27]. Shen Jiaxuan gives a broad definition of "perspective", that is, "perspective is the speaker's observation angle of objective situation, or the starting point of narrating objective situation" [30].

\subsection{The Speaker's Affect}

Many linguists employ different terms to refer to the emotional function of language [10, 12, 17]. The Appraisal Theory founded by Martin et al. on the basis of Systemic Functional Grammar states that AFFEC system is the resource to explain linguistic phenomena, which can explain the emotional response of language users to behaviors, speech production and products [19]. Shen Jiaxuan points out that the term "affect" should be understood broadly, including emotion, intention, attitude, etc. For an utterance, it is hard to distinguish its part of expressing propositional content from its part of expressing emotion [30]. Almost every aspect of the language system can express emotion. In addition, the objects of expression elements in utterances are also various, which can be a reference object, a proposition, or even a series of propositions.

In real life, through the accumulation of life experience, everyone has formed a complete emotional system, such as like, love, approval, interest, reflecting a positive evaluation; disgust, hatred, opposition, not interested, reflecting a negative evaluation. Emotion is caused by objective things, but it reflects the significance of objective things to individuals, and the relationship between objective things and human needs instead of the objective things themselves. Human needs are restricted by social and historical conditions, because needs are not only the reflection of individual needs, but also the reflection of social needs. Of course, the sociality of emotion does not erase the personality characteristics of emotion. Emotion has its individual color, because emotion itself is a kind of subjective consciousness experience. Even if it is the same stimulus, it can't be reasoned that it will cause everyone the same emotion.

When we talk, we often can't state one thing purely and objectively. In most cases, each utterance we speak does carry our emotion. Language has the basic function of expressing the speaker's feelings, attitudes and opinions, which is as important as the function of describing things. Therefore, in the process of communication, we should not only master the propositional content expressed by the speaker, but also understand the emotional orientation of the speaker for the proposition. Prosody change, modal particles, affixes, pronouns, adverbs, tense and aspect markers, modal verbs, word order, repetition and other means can be used to express emotions, which involve various aspects of speech, word formation, grammar and discourse structure [22].

\subsection{The Speaker's Epistemic Status}

People's cognition is based on the objective world, so people's perception of the objective world has the same aspect; on the other hand, people's cognition of the objective world is permeated with subjective factors, which provides the possibility for the differences of cognition, so different people's cognition of the same thing will have certain differences. In language, "epistemic status" is mainly related to the category of modality, so it can also be called "epistemic modality". Modality is a semantic category and a kind of conceptual type of human thinking. The study of modality started from the field of logic. Since the sixties and seventies of last century, the field of linguistics began to draw on the research findings of modal logic to study modality. Epistemic modality is an important type of modality, which has been widely concerned by a host of scholars [10, 17, 23-26].

Lyons believes that modality is the non-factuality in a sentence, which expresses the speaker's views and attitudes towards the proposition or the situation described by the proposition. It is not limited to modal verbs. Modal adverbs, modal adjectives and tenses can also express modal meanings. Lyons divides modality into epistemic modality and deontic modality. Epistemic modality involves whether the propositional content of utterance is known or believed, and can be divided into objective and subjective categories. Deontic modality "is concerned with the necessity or possibility of acts performed by morally responsible agents". Deontic modality is mostly manifested as directives, which is closely related to truth value, future and some source or reason [17].

Perkins defines modality as "the conceptual context in which an event or proposition is established or not established, that is, the so-called possible world" [26]. Besides what Lyons has mentioned, modal expressions include quasi auxiliary modal expression, modal nominal modal expression, modal verbal expression, conditional sentence and interrogative sentence. Perkins tries to explain these expressions in an all-round way, and defines modality from the perspective of possible world, which can be divided into epistemic modality, deontic modality and dynamic modality [26]. 
According to Halliday, modality is an important part of interpersonal function, which is the judgment and evaluation made by the speaker on the success and effectiveness of the proposition, or the obligation required by the other party in the proposal, or the personal will to be expressed in the provision. He holds that between yes and no, "there are intermediate degrees: various kinds of indeterminacy that fall in between, like 'sometimes' or 'maybe'. These intermediate degrees, between the positive and negative poles, are known collectively as modality" [10]. Halliday also puts forward the concept of metaphors of modality, which is regarded as an integral part of interpersonal metaphor. On this basis, he proposes the subjective and objective orientations of modality.

\section{The Intersubjectivity of Language}

The concept of intersubjectivity was first put forward by phenomenologist Husserl. Husserl tries to establish the parallel relation between the transcendental ego through the concept of intersubjectivity. In verbal communication, there is such a relationship between the speaker and the hearer. when the speaker utters a sentence, the hearer knows in his mind that based on his experience, he can understand the meaning of the sentence or make some kind of communicative response. However, Husserl did not discuss the communicative function of language expression, but focused on the analysis of other people's experience construction.

Intersubjectivity is also the core idea of Bakhtin's communication thought. Bakhtin regards language and ideology as the fundamental social facts, and believes that the growth of individuals comes from the intersubjective field of social interaction between language and ideology. It is the sociality and intersubjectivity of language and ideology that make dialogue the inherent nature of discourse. In other words, discourse originates from social dialogue and is a part of social dialogue. A person's utterance is always composed of other people's utterance, and always seek others' response [2].

From the linguistic point of view, intersubjectivity is mainly related to discourse. When discussing subjectivity, Benveniste points out that the reason why language is possible is that every speaker stands on his own as the subject and calls himself "I", and the subject "I" also predetermines the response of "I" - the existence of "you". I say "you" to this response, and it says "you" to me. Therefore, Benveniste believes that it is the interaction between the speaker and the language that makes linguistic communication possible [3].

Other scholars also have different definitions of intersubjectivity. Traugott holds that intersubjectivity refers to the speaker's concern about the "self" of the hearer in a clear language form, which can be reflected in the cognitive sense, that is, the hearer's attitude towards the propositional content; but more in the social sense, that is, the concern about the "face" or "image needs" of the hearer [31]. Schiffrin points out that "intersubjectivity" involves not only the speaker's attention to the hearer, but also the hearer's understanding and response to the discourse [28]. Nuyts believes that "if the speaker evaluates himself completely, such evaluation is subjective; if the speaker implies that he will share his self-evaluation with others (possibly including the hearer), such evaluation has intersubjectivity" [28]. In Verhagen's view, subjectivity highlights the perspective of the subject in the relationship between the cognitive subject and the object, as well as the focus on the cognitive construal of the "subject". Intersubjectivity is the reflection of the basic cognitive cooperative abilities of both parties in verbal communication, and it is the focus on the cognitive construal of "inter subjects" [32], which is a further enrichment and supplement of the concept of subjectivity from the cognitive level.

In contrast, Traugott's understanding of "intersubjectivity" is closest to Benveniste's interpretation. From a diachronic perspective, subjectivity precedes intersubjectivity. intersubjectivity derives from subjectivity and takes the latter as implication. In other words, if a language form has intersubjectivity, it must also have subjectivity. In verbal communication, the speaker always expresses his position, opinion or attitude towards the proposition. When these positions, views or attitudes imply the speaker's recognition and concern for the listener, intersubjectivity arises.

\section{Concluding Remarks}

In the 20th century, a "linguistic turn" took place in western philosophy both in the European continent and in the British and American world. Language is not only a means or medium to express philosophical thoughts, but also one of the objects of philosophical research. We use language to talk about the world and grasp reality through language; the world or reality enters our cognition through entering language. Structural linguistics and its derivative theories, which originated from Saussure, have made great achievements in language research. However, as Li Hongru says, "while affirming its great achievements, it is not difficult to find its fatal defects. One of these defects is that it has eliminated the human factor in language and eliminated the subject" [15]. However, as the agent of cognition and language formation, man plays the most critical role in the whole process of its formation. Without revealing the human factor in discourse, we cannot fully understand the nature of language, nor can we successfully communicate with each other. As a result, the trend of human-centered development of linguistics has become increasingly obvious, and the speaker's factor in language now has, and will definitely have a strong vitality in the future linguistic research.

\section{Acknowledgements}

This paper is funded by the Research Project Supported by Shanxi Scholarship Council of China.

\section{References}

[1] Austin, J. L. 1962. How to do Things with Words. Oxford: Oxford University Press. 
[2] Bakhtin, M. 1981. The Dialogic Imagination: Four Essays. M. Holquist (ed.). C. Emerson and M. Holquist (trans.). Austin: University of Texas Press.

[3] Benveniste, E. 1971. Problems in General Linguistics. Coral Gables, FL: University of Miami Press.

[4] Bréal, M. 1964. Semantics: Studies in the Science of Meaning. New York: Dover.

[5] Bühler, K. 1990. Theory of Language: The Representational Function of Language. Amsterdam: Benjamins.

[6] Butler, C. S. 1985. Systemic Linguistics: Theory and Applications. London: Batsford.

[7] Clark, H. H. 1973. Space, time, semantics and the child. In T. Moore (ed.). Cognitive Development and the Acquisition of Language. New York: Academic Press.

[8] Finegan, E. 1995. Subjectivity and Subjectification: An Introduction. In Stein, D. and Wright, S. (eds.). Subjectivity and Subjectification. Cambridge: Cambridge University Press, $1-15$.

[9] Grice, H. P. 1975. Logic and conversation. In S. Davis (ed.). Pragmatics: A Reader. Oxford: Oxford University Press, 305-315.

[10] Halliday, M. A. K. 1994. An Introduction to Functional Grammar (2nd ed.). London: Edward Arnold.

[11] He Ziran, 2007, New Development in Pragmatics: Relevance, Adaptation, Memetics. Shanghai: Shanghai Education Press.

[12] Jakobson, R. 1957. Shifters, Verbal Categories, and the Russian Verb. Cambridge MA: Harvard University Russian Language Project.

[13] Jakobson, R. 1960. Linguistics and poetics. In T. A. Sebeok (ed.). Style in Language. Cambridge, Mass: MIT Press, 350-377.

[14] Langacker, R. W. 1987. Foundation of Cognitive Grammar (Vol. 1): Theoretical Prerequisites. Stanford: Stanford University Press.

[15] Li Hongru, 2001, A study on the development of semantic theory from the logic and philosophical perspectives. Foreign Language Research (1): 31-38.

[16] Liu Jin, 2010. Perspective in Language Expression. Foreign Language Research (4): 40-43.

[17] Lyons, J. 1977. Semantics. Cambridge: Cambridge University Press.
[18] Lyons, J. 1995. Linguistic Semantics: An Introduction. Cambridge: Cambridge University Press.

[19] Martin, J. R. and P. White. 2005. The Language of Evaluation: Appraisal in English. New York: Palgrave MacMillan.

[20] Miller, G. and P. Johnson-Laird. 1976. Language and Perception. Cambridge: Cambridge University Press.

[21] Nuyts, J. 2005. Modality: Overview and Linguistic Issues. In W. Frawley (ed.). The Expression of Modality. Berlin: Mouton de Gruyter.

[22] Ochs, E and B. Schieffelin. 1989. Language has a heart. Text 9.1 (Special Issue on the pragmatics of affect). 7-25.

[23] Palmer, F. 1986. Mood and Modality. Cambridge: Cambridge University Press.

[24] Palmer, F. 1990. Modality and the English Modals (2nd ed). London: Longman.

[25] Palmer, F. 2001. Mood and Modality (2nd edition). Cambridge: Cambridge University Press.

[26] Perkins, M. 1983. Modal Expressions in English. London: Frances Printer.

[27] Sanders, J. and G. Redeker. 1996. Perspective and the representation of speech and thought in narrative discourse. In G. Fauconnier and E. Sweetser (eds.) Spaces, Worlds and Grammar. Chicago/London: University of Chicago Press, 290-317.

[28] Schiffrin, D. 1990. The principle of intersubjectivity in communication and conversation. Semiotica 80: 121-151.

[29] Sperber, D and D. Wilson. 1986/1995. Relevance: Communication and Cognition. Oxford: Blackwell.

[30] Shen Jiaxuan, 2001. A Survey of studies on subjectivity and subjectivisation. Foreign Language Teaching and Research (4): 268-275.

[31] Traugott, E. C. 1999. The rhetoric of counter-expectation in semantic change: A study in subjectification. In A. Blank and P. Koch (eds.). Historical Semantics and Cognition. Berlin/New York: Mouton de Gruyter. 177-196.

[32] Verhagen, A. 2005. Constructions of Intersubjectivity. Oxford: Oxford University Press.

[33] Wang Yin, 2005. On embodiment of language - from the perspective of embodied philosophy and cognitive linguistics. Foreign Language Teaching and Research (1): 37-43. 